\title{
The effect of myasthenia gravis on pregnancy and the newborn
}

Carlayne E. Jackson, MD

\section{What is myasthenia gravis (MG)?}

MG is a disorder caused by proteins in the blood called "antibodies." More information about MG can be found on the next page. MG is common in women who are in their child-bearing years. It is important to evaluate the effects that the disease may have on pregnancy, delivery, and the newborn.

\section{Whom did the researchers include in the study?}

In this issue of Neurology, Hoff et al. evaluated women with and without MG during pregnancy. They studied the occurrence of complications during delivery in these women and the health of their babies. ${ }^{1}$ The data for the study came from the Medical Birth Registry of Norway between 1967 and 2000. The authors identified 127 births by 79 MG patients and compared delivery complications and newborn health to a group of women without MG who gave birth to 1.9 million babies.

\section{What effect did MG have on the mothers and newborns?}

Information about the mothers and newborns in both groups is given in table 1. Mothers with MG were older than the mothers without MG. They were also more likely to deliver in a university hospital. There was no difference in the average birth weight, age at birth, or death rate of the newborns between the two groups.

\section{What effects did MG have on the delivery?}

The number of births requiring medications to induce labor was not increased in MG mothers. However, the percentage requiring cesarean section was doubled compared with the reference group $(17.6 \%$ in the MG mothers compared with $8.6 \%$ in mothers without MG). The use of forceps or a vacuum during delivery was higher in the MG group before 1981, but no different from the group without MG after 1981. Premature rupture of the membranes holding the amniotic fluid was the only complication that was higher in the mothers with MG.

\section{What effect did MG have on complications in the newborns?}

Serious complications requiring the transfer of the newborn to the pedi-

Table 1 Patient characteristics

\begin{tabular}{lcc}
\hline Characteristic & Women with MG & Women without MG \\
\hline Number of deliveries & 127 & $1,988,865$ \\
Mean age, y & $29^{*}$ & 27 \\
Birth at university hospital & $68(53.5 \%)^{*}$ & $501,959(25.2 \%)$ \\
Gestational age, wk & 39.4 & 39.6 \\
Birth weight, grams & 3,483 & 3,485 \\
\hline
\end{tabular}

\footnotetext{
* Statistically significant difference between the two groups.
}

atric intensive care unit occurred in $21.3 \%$ of the children born to mothers with MG compared with $2 \%$ born to mothers without MG. Neonatal MG is caused by transfer of MG antibodies between the mother and newborn. It leads to weakness in the newborns. Neonatal MG was reported in $4 \%$ of newborns of mothers with MG. Five of the children (3.7\%) in the MG group had birth defects that were classified as severe. This was not significantly higher than the group whose mothers did not have MG.

\section{What does this study mean?}

This study supports previous studies confirming that MG may have effects on the mother during pregnancy. MG may also increase the risk for complications during delivery. Intensive care facilities for the newborn should be immediately available because of the possibility of neonatal MG. This should not prevent women with MG from considering pregnancy. Women with MG who choose to become pregnant should have good prenatal care with doctors who are experienced in treating MG. They should also deliver their babies in a hospital experienced in handling complications should they arise.

\section{Reference}

1. Hoff JM, Daltveit AK, Gilhus NE. Myasthenia gravis: consequences for pregnancy, delivery, and the newborn. Neurology 2003;61: 1362-1366. 


\section{What is Myasthenia Gravis $(M G)$ ?}

MG is a chronic autoimmune disease that causes muscle weakness. In people with $\mathrm{MG}$, cells of the immune system make proteins called antibodies that block nerve impulses to their muscles.

\section{What are the symptoms of MG?}

The major symptom of MG is muscle weakness that is worsened by fatigue and generally improves with rest. Muscles that control eye movements, facial expression, chewing, talking, and swallowing are often involved. The muscles in the neck, arms and legs may also be affected. In more severe cases, the breathing muscles can be involved causing shortness of breath.

\section{What causes the symptoms of MG?}

MG is caused by a problem with nerve impulses getting to muscles. Normally when impulses travel down the nerve, the nerve endings release a protein called acetylcholine. Acetylcholine is like a key that fits into the acetylcholine receptor, which is like a lock. With the proper fit, the door is opened and a signal is sent to the muscle to do its job. People with MG make antibodies to the acetylcholine receptor. Acetylcholine antibodies fit into the receptor, but the door does not open and no signal is sent to the muscle. This leads to muscle weakness.

\section{Who gets MG?}

MG occurs in all ethnic groups and in both men and women. It most commonly affects women under 40 years of age and men over 60 years of age but can occur at any age. When a mother with MG is pregnant the acetylcholine receptor antibodies can transfer to the fetus.
When this happens, the baby can have temporary symptoms of weakness similar to the mother. This is called "neonatal MG." Muscle weakness may be noticed at birth or begin within the first week of life in these children and may require care in an intensive care unit. Symptoms from neonatal MG usually disappear within a few weeks after birth and do not recur.

\section{How do you diagnose MG?}

If $M G$ is suspected, several tests are available to confirm the diagnosis.

Acetylcholine receptor antibody test. A special blood test can detect the presence of the acetylcholine receptor antibodies. Most patients with MG have high levels of these antibodies. However, antibodies may not be detected in about 15\% of MG patients.

Edrophonium test. Edrophonium, a chemical that prevents the breakdown of acetylcholine, is injected into the vein. This increases the levels of acetylcholine available to the acetylcholine receptor and may temporarily relieve the weakness caused by MG.

Repetitive stimulation of muscle fibers. Another method to confirm the diagnosis of MG is called a repetitive stimulation test. This study involves repeated electrical shocks to a nerve in the arm or face. The response from the muscle which is stimulated by that nerve is recorded. In MG, the response from the muscle shows evidence of fatigue.

Chest computed tomography (CT) or magnetic resonance imaging $(M R I)$. These tests are used to identify an abnormal thymus gland or the presence of a thymoma (tumor of the thymus gland). In adults with MG, the thymus gland is often ab- normal. Scientists believe the thymus gland may incorrectly instruct the immune system to make acetylcholine receptor antibodies in people with MG. Some people with MG develop thymomas.

\section{How do you treat MG?}

Medications. MG can be controlled. Some medications act like edrophonium and increase the amount of acetylcholine around the muscle, improving muscle strength. Others suppress the production of acetylcholine receptor antibodies.

Thymectomy. Thymectomy is the surgical removal of the thymus gland. Thymectomy improves MG symptoms in certain patients and may cure some, possibly by rebalancing the immune system.

Other treatments. Plasmapheresis is a procedure that removes abnormal antibodies from the blood. Highdose intravenous immune globulin temporarily modifies the immune system and provides the body with normal antibodies from donated blood. Both of these have also been used to treat MG.

\section{What is the prognosis of MG?}

With treatment, the outlook for most patients with MG is bright. They can expect to lead normal or nearly normal lives. It is important for people with MG to talk to their doctors about the best treatment for them.

\section{For more information}

American Academy of Neurology, www.aan.com

Myasthenia Gravis Foundation of America, Inc., www.myasthenia.org

Muscular Dystrophy Association, www.mdausa.org 


\title{
Neurology
}

\author{
The effect of myasthenia gravis on pregnancy and the newborn \\ Carlayne E. Jackson \\ Neurology 2003;61;1459-1460 \\ DOI 10.1212/WNL.61.10.1459
}

This information is current as of November 24, 2003

Updated Information \&

Services

References

Citations

Permissions \& Licensing

Reprints including high resolution figures, can be found at: http://n.neurology.org/content/61/10/1459.full

This article cites 1 articles, 1 of which you can access for free at: http://n.neurology.org/content/61/10/1459.full\#ref-list-1

This article has been cited by 1 HighWire-hosted articles: http://n.neurology.org/content/61/10/1459.full\#\#otherarticles

Information about reproducing this article in parts (figures,tables) or in its entirety can be found online at:

http://www.neurology.org/about/about_the_journal\#permissions

Information about ordering reprints can be found online:

http://n.neurology.org/subscribers/advertise

Neurology ${ }^{\circledR}$ is the official journal of the American Academy of Neurology. Published continuously since 1951, it is now a weekly with 48 issues per year. Copyright . All rights reserved. Print ISSN: 0028-3878. Online ISSN: 1526-632X.

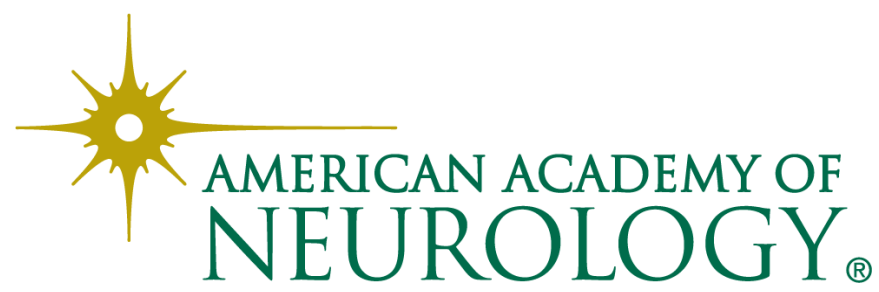

